NASA Technical Memoranáum 87292

\title{
Influence of Fatigue Crack Wake Length and State of Stress on Crack Closure
}

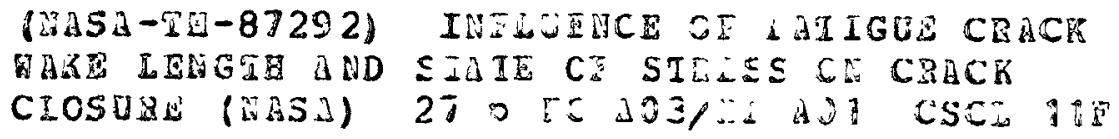

Wack Telesman and Douglas M. Fisher

Lewis Research Center

Cleveland, Ohio

Prepared for the

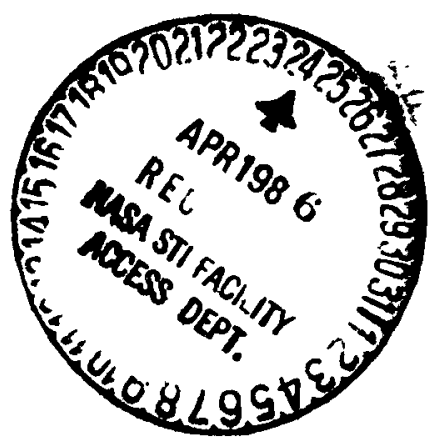

International Symposium on Fatigue Crack Closure sponsored by the American Society for Testing and Materials Charleston, South Carolina, May 1-2, 1986 
INFLUENCE OF FATIGUE CRACK WAKE LENGTH AND STATE OF STRESS ON CRACK CLOSURE

Jack Telesman and Douglas M. Fisher

National Aeronautics and Space Administration

Lewis Research Center

Cleveland, Ohio 44735

\section{ABSTRACT}

The location of crack closure with respect to crack wake and specimen thickness under different loading conditions was determined. The rate of increase of $K_{C L}$ in the crack wake was found to be significantly higher for plasticity induced closure in comparison to roughness induced closure.

Roughness induced closure was uniform throughout the thickness of the specimen while plasticity induced closure levels were 50 percent higher in the near surface region than in the mid-thickness. The influence of state of stress on low-high load interaction effects was also examined. Load interaction effects differed depending upon the state of stress and were explained in terms of $\Delta K_{e f f}$ 


\section{NOMENCLLATURE}
$a / w$
ratio of crack length to width
CT
compact tension
$\mathrm{da} / \mathrm{dN}$
crack growth rate
FCP
fatigue crack propagation
${ }^{\mathrm{K}} \mathrm{CL}$
closure stress intensity
$K_{C L P}$
closure stress intensity due to plasticity
${ }^{K}$ CLR
closure stress intensity due to roughness
Ko
opening stress intensity
$\mathrm{R}$
load ratio (minimum load/maximum load)
$r_{p}$
plastic zone size
$\Delta K_{\text {app }}, \Delta K \quad K_{\max }-K_{\min }$
$\Delta K_{\text {eff }} \quad K_{\max }-K_{0}$
oys
yield strength

\section{INTRODUCTION}

In recent years much attention has been focused on fatigue crack closure as introduced by Elber [1]. He suggested that crack surfaces can close before the minimum load is reached due to the residual plasticity induced displacements in the crack wake. He further suggested that the fatigue crack propagation (FCP) rate is a function of the stress intensity range when the crack tip is open. Thus, FCP is dependent on $\Delta K_{\text {eff }}$ and not on $\Delta K_{a p p}$. More recently, a number of researchers [2-4] have shown that in addition to plasticity, crack closure can also be caused by the mismatch of fracture surfaces (roughness) or by a build up of the oxide layers on the fracture surface.

The importance of crack closure in present day research on FCP can be seen by the application of this concept to the research of such diverse topics as vartable amplitude loading [5], near-threshold behavior $[6,7]$ and the 
accelerated growth of short cracks $[8,9]$. However, many questions regarding the actual mechanisms of crack closure still persist. For instance, the location and distribution of closure stresses in the crack wake is not well understood. It has been suggested that crack closure is a function of crack wake length [10]. Zaiken and Ritchie [11] as well as others [12,13] have shown that in the near-threshold regime where roughness induced closure is important, removal of crack wake reduces closure. However, the influence of crack wake is unknown at higher stress intensities where plasticity induced closure is dominant. To further complicate the picture, surface effects due to localized plane stress conditions can also significantly contribute to crack closure. Thus, in order to better understand the different closure mechanisms, there is a need to determine how and where closure occurs. It is also important to understand the mechanism under which predominantly roughness or oxide induced closure changes to plasticity induced closure.

Crack closure may also be important in understanding load sequence interaction effects which are not well understood. Review of the literature reveals some controversy regarding the FCP behavior immediately following a low-high loading sequence. VonEuw et al. [14] observed a transient region after the transition to a higher $\triangle K$ where initial FCP rates were higher than expected. However, others $[15,16]$ concluded that no load interactions take place when this type of loading is applied. A very interesting finding relative to a low-high loading sequence behavior was documented recently by Schulte et al. [17]. They also noted a region of higher than expected FCP rates after the transition to a higher $\triangle K$ when FCP rates were measured at the specimen surface. However, when the FCP rates of the same specimen were evaluated by using a striation counting technique in a region away from the surface, no initial acceleration of FCP rates was detected. The above 
observations suggest that plane stress and plane strain variations should be considered in the effort to explain loading sequence effects.

A test program was developed to consider the effects of crack wake and specimen thickness on crack closure, as well as the influence of the stress state on low-high load interactions.

EXPERIMENTAL PROCEDURE

For the FCP studies, compact tension (CT), specimens oriented in a long transverse orientation were machined from a $3.2 \mathrm{~mm}$ thick sheet of 7075-T6 aluminum with tensile properties as detailed in Table 1. The width of the CT specimens was $38.1 \mathrm{~mm}$, the initial a/w ratio was 0.2 , and the thickness was that of the as received sheet unless otherwise indicated. All tests were performed using a closed loop servohydraulic fatigue machine. All testing was done at an $R$ ratio of 0.7 and frequency of $20 \mathrm{~Hz}$ in an ambient air environment. Testing was computer controlled using a compliance technique to maintain either a constant stress intensity range or load range and to determine crack length. Occasional optical readings were made to confirm the compliance readings of the crack length.

Constant load amplitude tests were performed on the $3.2 \mathrm{~mm}$ thick specimens to obtain baseline data. Two types of tests were conducted, wake removal and surface removal, to determine the effect of crack wake length and thickness on crack closure. Initial preparation of specimens for both test types was precracking under constant stress intensity ranges of $2.5,8.8$, and $17.6 \mathrm{MPa} \sqrt{\mathrm{m}}$ until an $a / w$ of 0.4 was reached. For the crack wake removal experiments, increments of the fatigued crack wake were removed using a $0.5 \mathrm{~mm}$ thick jewelers saw, and closure loads determined. The closure loads were taken at the first deviation from linearity in the unloading portion of the load displacement curves. In the surface removal tests, specimen thickness was 
reduced incrementally by machining equal amounts from each surface. At each thickness closure loads were determined by the above mentioned procedure.

The low-high load sequence tests to evaluate stress state influence were performed on as-received and $1.1 \mathrm{~mm}$ thicknesses. The low-high load sequence tests performed on the $3.2 \mathrm{~mm}$ thick specimens consisted of precracking duplicate specimens at a $\Delta K$ of $4.4 \mathrm{MPa} \sqrt{\mathrm{m}}$ from the initial a/w of 0.2 to 0.35. The stress intensity range was then increased to a $\Delta K$ of $13.4 \mathrm{MPa} \sqrt{\mathrm{m}}$. In addition, separate CT specimens were tested at a constant $\Delta K$ of $4.4 M P a \sqrt{m}$ and $13.4 \mathrm{Mpa} \sqrt{\mathrm{m}}$. For each of these constant $\Delta K$ specimens load-displacement curves were obtained, from which closure loads and the corresponding $\mathrm{K}_{\mathrm{CL}}$ values were determined. For the closure reading tests the frequency was decreased to $0.05 \mathrm{~Hz}$. A similar procedure was used for the $1.1 \mathrm{~mm}$ thick specimens, however, the low-high loading sequence consisted of a transition from a $\Delta K$ of $6.6 \mathrm{MPa} \sqrt{\mathrm{m}}$ to a $\Delta K$ of $16.0 \mathrm{MPa} \sqrt{\mathrm{m}}$. Again closure loads for the thinner specimens were obtained by testing separate specimens individualty fatigued at the above two stress intensity ranges. The entire program test matrix is shown in Table 2 .

To determine the FCP rates as a function of crack length from the transition to a higher $\Delta K$, fractographic analysis of the striation spacings was performed using a scanning electron microscope. All fractographs were taken using a $0^{\circ}$ tilt to limit possible distortions of striation spacings used to calculate FCP rates.

\section{RESULTS AND DISCUSSION Baseline FCP Data}

The baseline fatigue crack propagation curve obtained for the 7075-T6 alloy is shown in Fig. 1. An equation fitting the straight line portion of the curve (i.e., crack growth data for $\Delta K>8 M P a \sqrt{m}$ ) is: 


$$
\frac{d a}{d N}=1.236 \times 10^{10} \Delta K^{3.07}
$$

where $d a / d N$ is the crack growth expressed in m/cycle and $\Delta K$ is in $M P a \sqrt{m}$.

\section{Removal of Crack Wake}

The data showing crack closure stress intensity' as a function of crack wake length at $\Delta K$ of $2.5,8.8$, and $17.6 \mathrm{MPa} \sqrt{\mathrm{m}}$ is shown in Fig. 2 . These results show a significant difference in behavior. The test conducted at the near-threshold stress intensity of $2.5 \mathrm{MPa} \sqrt{\mathrm{m}}$, showed $\mathrm{K}_{\mathrm{CL}}$ decreasing when the remaining crack wake reached approximately $3 \mathrm{~mm}$. The $\mathrm{K}_{\mathrm{CL}}$ decreased gradualiy with further removal of crack wake. At the shortest crack wake for which valid measurements were obtained of $1.4 \mathrm{~mm}, K_{C L}$ was measured to be $0.75 \mathrm{MPa} / \overline{\mathrm{m}}$ which was approximately 60 percent of the initial full crack wake value. These results agree with trends observed by others in both aluminum [11] and steel [13] where it was observed that in the near-threshold region $K_{C L}$ started decreasing when the length of the crack wake is reduced to 2 to $4 \mathrm{~mm}$.

In contrast to the tests performed at $\Delta K$ of $2.5 \mathrm{MPa} \sqrt{\mathrm{m}}$, no change in $K_{C L}$ with the removal of the crack wake was detected for tests performed at $\Delta K$ of 8.8 and $17.6 \mathrm{MPa} \sqrt{\mathrm{m}}$ even though the shortest remaining crack wakes for which data was obtained were respectively 0.33 and $0.68 \mathrm{~mm}$. Since there can be no closure without crack wake, the results indicate that closure load increases with respect to crack wake much more rapidly at $\Delta K$ of 8.8 and $17.6 \mathrm{MPa} \sqrt{\mathrm{m}}$ in comparison to a $\Delta K$ of $2.5 \mathrm{MPa} / \sqrt[\mathrm{m}]{ }$. The divergence in behavior suggests that different closure mechanisms control closure at near-threshold stress intensities than those controlling closure at higher stress intensities.

$I_{\text {For all conditions }} K_{0}$ was found to be approximately equal to $K_{C L}$ thus $\Delta K_{\text {eff }}=K_{\max }-K_{C L}$. 
In the wear experiments, which were conducted to examine the effects of magnetic-head wear on magnetic signals, a newly recorded tape (11 $\mathrm{m}$ long) was first run and the standard signal $G_{1}$ was read back. An unrecorded tape (230 $\mathrm{m}$ long) was repeatediy run over a desired head sliding distance. During the sliding process the 11-m-long recorded tape, which was used to read back signals $G_{n}$ at various stages of the experiment, was replaced several times. Electron Diffraction and Depth Profiling

The sliding surfaces of the magnetic heads were depth profiled to examine the crystalline states as a function of depth. The etching was done with hydrochloric acid at $50 \pm 1{ }^{\circ} \mathrm{C}$ for a predetermined etching time. The surfaces were examined by reflection electron diffraction in a transmission electron microscope. The acceleration voltage was 75 or $100 \mathrm{kV}$. The depth in terms of the etching time was obtained by using an optical interference microscope.

\section{RESULTS AND DISCUSSION \\ Crystalline State of Lapped Surface}

Sliding a lapping tape on a Mn-Zn ferrite magnetic head generated abrasion and developed a deformed layer on the ferrite surface. Figure 3 presents reflection diffraction patterns obtained from the abraded surface and the etched surfaces. The arcs in the electron diffraction pattern of the abraded surface are partial Debye-Scherrer rings that contain enlarged, streaked spots [Fig. 3(a)]. They indicate that a highly textured, surficial layer formed on the single-crystal magnetic head during the sliding of the lapping tape.

The surface etched to a depth of $0.3 \mu \mathrm{m}$ from the abraded surface shows an enlarged streak-spot pattern [Fig. 3(b)]. The streaking indicates a great amount of plastic deformation: that is, a highly strained single-crystal structure. A large number of line defects can cause streaking in a single-crystal diffraction pattern. 
The surface etched to a depth of $0.6 \mu \mathrm{m}$ shows Kikuchi lines (pairs of black and white parallel lines), which are an indication of the bulk single-crystal structure of a ferrite head containing no extrinsic mechanical stress [Fig. 3(c)]. Thus the total thickness of the deformed layers on the Mn-Zn ferrite head presented in Fig. 3 was less than $0.6 \mu \mathrm{m}$.

When lapping tape was again slid against the etched surface typified by Fig. $3(c)$, the polishing process reintroduced local surface stresses and redeveloped a deformed layer on the ferrite similar to that on the surface presented in Fig. 3(a).

\section{Effect of Crystal Structure on Magnetic Signals}

To determine how wear of the lapped magnetic head affects its crystalline state and magnetic signals, we ran the head against magnetic tapes (recorded and unrecorded) at an initial tape tension of $0.2 \mathrm{~N}$ and three head displacements for a sliding distance of $40 \mathrm{~km}$. The results are presented in Fig. 4(a). The readback signal amplitude (sensitivity) decreased rapidiy during the initial $20 \mathrm{~km}$ of tape sliding distance. It remained constant or decreased slightly over the next $20 \mathrm{~km}$.

Typical electron diffraction patterns taken from the lapped surfaces of the magnetic head before the sliding experiment and from the wear surfaces after $40 \mathrm{~km}$ of sliding are presented in $\mathrm{Fig} .4(\mathrm{~b})$ and (c). These diffraction patterns show that sliding action changed the highly textured, polycrystalline structure of the lapped head to a nearly amorphous structure. When a lapping tape was then slid against the wear surface of the lapped magnetic head, the nearly amorphous structure was removed and a highly textured, polycrystalline structure was reformed in the magnetic-head surficial layer. The lapping also restored the readback signal amplitude to the initial standard level $G_{1}$. In other words, lapping the wear surface of the magnetic head restored extrinsic magnetic properties. 
with the trends observed in the crack wake removal tests which also indicated the rapid growth of closure for a plasticity dominant closure mechanism.

Transition From Roughness to Plasticity Induced Closure

The experimental results obtained in this study shed some light on the conditions under which the transition from roughness to plasticity dominated closure mechanism occurs. It was shown that even under a predominant plane strain condition encountered in the specimens, tested at $\Delta K$ of $8.8 \mathrm{MPa} \sqrt{\mathrm{m}}$, plasticity induced closure plays an important role. Thus, the calculated overall state of stress of the specimen is not adequate for the determination of the type of predominant closure mechanism.

It can be postulated that

$$
K_{C L}=K_{C L R}+K_{C L P}
$$

where $K_{C L R}$ is the closure stress intensity due to roughness induced closure and $K_{C L P}$ is the plasticity induced closure. $K_{C L}$ is dominated by the area in the crack wake where the largest mismatch of the crack faces occur. It was shown that for the specimen tested at $\Delta K$ of $2.5 \mathrm{MPa} \sqrt{\mathrm{m}}$, the closure was uniform throughout the specimen thickness indicating that $K_{C L P}$ was considerably smaller than $K_{C L R}$ resulting in roughness dominated closure mechanism. Due to the considerably larger plane stress plastic zone sizes of the 8.8 and $77.6 \mathrm{MPa} \sqrt{\mathrm{m}}$ specimens (Table 3 ), the near surface displacements at these stress intensities were also considerably larger in comparison to the test performed at the near-threshold stress intensity. This resulted in confining most of the closure near the surface and promoted plasticity induced closure. It is clear that the transition from predominantly roughness induced to plasticity induced closure occurs when $K_{\text {CLP }}$ becomes a significant component of the total measured $\mathrm{K}_{\mathrm{CL}}$. More research is required to obtain a 
more quantitative description of the transition by measuring both the thru-thickness as well as near surface displacements at various applied stress intensities.

\section{Low-High Loading}

While some researchers $[15,16]$ have not found any load interaction effects when a low-high loading sequence is applied, others [14] found initially higher than expected FCP rates after transition to a higher $\triangle K$. Hertzberg [20] proposed that these initially higher than expected FCP rates can be explained by the influence of the transitional behavior of crack closure on $\Delta K_{e f f}$. He argued that initially after the transition to a higher $\Delta K$, the material still experiences low closure loads and hence a greater $\Delta K_{\text {eff }}$. Only when the new larger deformed zone created by the higher loads begins to interfere in the wake of the crack front, does the closure level begin to rise, decreasing the

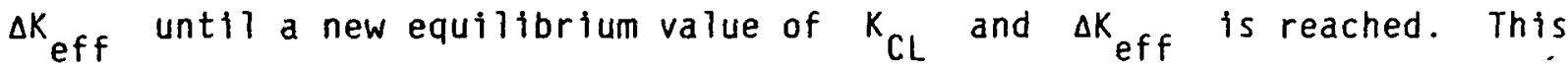
process is shown schematically in Fig. 5 .

In order to evaluate Hertzberg's hypothesis, baseline FCP rates as a function of $\Delta K_{\text {eff }}$ were determined and are shown in Fig. 6 .

A Paris type equation fitting this data is:

$$
\frac{\mathrm{da}}{\mathrm{dN}}=1.445 \times 10^{-10} \Delta K_{\mathrm{eff}}^{3.21}
$$

where $\mathrm{da} / \mathrm{dN}$ is in $\mathrm{m} / \mathrm{cycle}$ and $\Delta \mathrm{K}_{\text {eff }}$ is in $\mathrm{MPa} \sqrt{\mathrm{m}}$. The least square correlation coefficient for this equation is 0.997 .

The results of the low-high loading sequence tests are shown in Figs. 7 and 8 . As shown in these figures, there exists a substantial difference in the behavior between the $3.2 \mathrm{~mm}$ and the $1.1 \mathrm{~mm}$ thick specimens. The thick specimens exhibited no noticeable change in FCP rates as a function of fatigue crack distance after the transition to a higher $\Delta K$ as shown in Fig. 7 . However, for the thin specimens (Fig. 8) immediately following the transition, 
the FCP rates were initially high and progressively decreased till a plateau was reached. For these specimens, the FCP rates immediately after the transition were approximately twice as high as the rates in the plateau region. The above results were obtained by measuring striation spacings. Typical fractographs used for this purpose are shown in Figs. 9 and 10.

The validity of using the striation counting technique to determine FCP rates was evaluated by comparing the growth rates obtained by this method to rates measured by the compliance technique. Striation measurements consistently showed slightly lower growth rates (up to 25 percent) possibly due to a small tilt of the fracture features with the respect to the screen projection. Some scatter within the striation measurements was also present. The scatter band was approximately \pm 10 percent of the mean value. This degree of scatter is reasonable when it is considered that a striation counting technique measures localized growth rates. These rates can be influenced by such factors as grain orientation and the presence of inhomogeneities such as inclusions.

The question arises why there is a difference in behavior between the thick and thin specimens? The difference in observed behavior may be explained by evaluating the state of stress of each specimen and its effect on $\mathrm{K}_{\mathrm{CL}}$. The applied stress intensities and specimen thicknesses were chosen to evaluate both plane strain and plane stress effects. The $3.2 \mathrm{~mm}$ thick specimen still met the ASTM E399 thickness criteria for a predominant plane strain condition even after the transition to a higher $\Delta K$. However the $1.1 \mathrm{~mm}$ thick specimen was in a substantially plane stress state after transition. These differences in the state of stress had a considerable effect on $\mathrm{K}_{\mathrm{CL}}$ as is described below.

Equilibrium $K_{C L}$ values for all applied stress intensities used in this part of the program are shown in Table 4 . For the $1.1 \mathrm{~mm}$ thick specimens, the 
$\mathrm{K}_{\mathrm{CL}}$ was measured to be $2.3 \mathrm{MPa} \sqrt{\mathrm{m}}$ at the lower stress intensity and $5.3 \mathrm{MPa} \cdot \sqrt{\mathrm{m}}$ at the higher stress intensity. This substantial difference in $\mathrm{K}_{\mathrm{CL}}$ values is not surprising considering that the lower stress intensity resulted in a predominant plane strain state while the higher stress intensity resulted in existence of a substantial amount of plane stress. If it is assumed that Hertzberg's transition hypothesis is correct (Fig. 5), then the accelerated FCP rates immediately after transition to a higher $\Delta K$ can be predicted by the use of the da/dn- $\Delta K_{\text {eff }}$ relationship (Eq. (3)). By substituting the appropriate $\Delta K_{\text {eff }}$ values into this equation, a predicted $F C P$ rate of $9.5 \times 10^{-7} \mathrm{~m} /$ cycle is obtained. The FCP rate obtained from striation spacing measurements, shown in Figs. 7 and 8 , is $1 \times 10^{-6} \mathrm{~m} /$ cycle. The crack closure hypothesis (Fig. 5) also predicts that after a certain amount of crack growth, an equilibrium FCP rate should be reached corresponding to the baseline data. The predicted FCP rate at equilibrium using Eq. (3) is $4.8 \times 10^{-7} \mathrm{~m} / \mathrm{cycle}$. The actual FCP rate as measured from striation spacings is $5 \times 10^{-7} \mathrm{~m} / \mathrm{cyc}$ le. Thus the crack closure hypothesis predicts the observed behavior very well in the case of the thin specimens.

The acceleration of the FCP rates for the thin specimen, after the transition to a higher $\Delta K$ lasted for $0.2 \mathrm{~mm}$ of crack growth. It is interesting to note that the calculated plane stress plastic zone radius at the higher $\Delta K$ is $0.18 \mathrm{~mm}$ and is thus very close in size to the fatigue crack wake length over which accelerated FCP behavior was observed.

Assuming that the initial acceleration of FCP rates after the transition to a higher $\Delta K$ was caused by the transient crack closure behavior shown schematically in Fig. 5, it was possible to calculate the crack closure stress intensity as a function of fatigue crack wake after the transition. The calculations were performed by first solving Eq. (3) for the $\Delta K_{\text {eff }}$ values required to obtain the measured $F C P$ rates after the transition to a higher 
$\Delta K$ (Fig. 8). The obtained $\Delta K_{\text {eff }}$ values were subtracted from $K_{\max }$ to obtain the $K_{C L}$ values. The results of the calculation are shown in Fig. 11 and show equilibrium $\mathrm{K}_{\mathrm{CL}}$ is reached after $0.2 \mathrm{~mm}$ of crack growth. These results agree fairly well with the previously described surface removal test results which showed that $K_{C L}$ can be fully reestablished after $0.125 \mathrm{~mm}$ of crack growth in case of plasticity induced closure (Fig. 4).

The difference in the measured $K_{C L}$ values of the $3.2 \mathrm{~mm}$ the thick specimen between the lower and higher applied stress intensities is approximately $1 \mathrm{MPa} \sqrt{\mathrm{m}}$ as shown in Table 4 . This difference in $\mathrm{K}_{\mathrm{CL}}$ values is considerably smaller in comparison to the thin specimens. This result is not very surprising considering that for the thick specimens both the lower and higher applied $\Delta K^{\prime} s$ resulted in a predominant plane strain state of stress. The predicted FCP rates immediately after the transition from a low to higher $\triangle K$ as well as the predicted $F C P$ rates after a plateau has been reached were calculated using Eq. (3). The predicted FCP rates were respectively $5.9 \times 10^{-7} \mathrm{~m} /$ cycle and $4.6 \times 10^{-7} \mathrm{~m} /$ cycle immediately after transition and in the plateau region. The difference between these two values is only 30 percent as opposed to 130 percent for the thin specimen.

No initial acceleration of FCP rates was detected after the transition to a higher $\Delta K$ even though a 30 percent increase was predicted. However, it should be noted that the small scatter band present in obtaining the $K_{\mathrm{CL}}$ values can have a significant effect on the predicted FCP rates. Also, the 20 percent wide scatter band of the striation spacing measurements might have obscured the small initial acceleration. Thus, since the gradient in $\Delta K$ eff after transition is small, it is possible that a small acceleration of FCP rates did take place after the transition to a higher $\Delta K$, as predicted by the closure hypothesis, however, due to the scatter of the data no acceleration was detected. 


\section{CONCLUSIONS}

(1) Crack closure stress intensity was shown to increase at a significantiy higher rate with respect to the crack wake length for plasticity induced closure in comparison to roughness induced closure.

(2) For plasticity induced closure, no reduction in closure magnitude was found by removal of the crack wake to within $0.2 \mathrm{~mm}$ of the crack tip. For roughness induced closure, a reduction in closure magnitude was noted at a remaining crack wake length of $3 \mathrm{~mm}$.

(3) Roughness induced closure for specimen tested at $\Delta K$ of $2.5 \mathrm{MPa} \sqrt{\mathrm{m}}$ was found to be uniform throughout the thickness of the specimen, while near surface closure levels were approximately 50 percent higher than mid-thickness closure for specimens tested at $\Delta K$ of 8.8 and $17.6 \mathrm{MPa} \sqrt{\mathrm{m}}$.

(4) The $1.1 \mathrm{~mm}$ thick specimens exhibited a transient region of higher than expected FCP rates immediately after the transition from a low to high stress intensity. However, for the $3.2 \mathrm{~mm}$ thick specimen, no such load interaction effects were detected.

(5) This difference in transient behavior was explained by comparing $K_{C L}$ values for the lower and higher stress intensities. For the thin specimens, there was a large difference in $K_{C L}$ values between the lower and higher stress intensities due to change in state of stress resulting in a progressively decreasing $\Delta K_{\text {eff }}$ as a function of crack length from transition. For the thick specimens, in a predominant plane strain state, the difference in $K_{C L}$ was small creating negligible variation in $\Delta K_{\text {eff }}$ after transition to a higher $\Delta K$. 


\section{REFERENCES}

1. Elber, W, Engineering Fracture Mechanics, Vol. 2, No. 1, Jan. 1970, pp. $37-45$.

2. Walker, N., and Beevers, C.J., Fatigue of Engineering Materials and Structures, Vo1. 1, No. 1, 1979, pp. 135-148.

3. Minakawa, K., and McEvily, A.J., Scripta Metallurgica, Vol. 15, No. 6, June 1981, pp. 633-636.

4. Ritchie, R.0., and Suresh, S., Metallurgical Transactions A, Vol. 13A, No. 5, May 1982, pp. 937-940.

5. Dill, H.D., and Staff, C.R., "Effect of Fighter Attack Spectrum on Crack Growth," AFFOL-TR-76-712, Air Force Flight Dynamics Lab., Wright-Patterson Air Force Base, OH, 1977.

6. Blom, A.F., Fatigue Crack Growth Threshold Concepts, D.L. Davidson and S. Suresh, Eds., AIME, Warrendale, PA, 1984, pp. 263-280.

7. Beevers, C.J., Bell, K., and Karlson, R.L., in Fatique Crack Growth Threshold Concepts, D.L. Davidson and S. Suresh, Eds., AIME, Warrendale, PA, 1984, pp. 327-340.

8. Morris, W.L., James, M.R., and Buck, 0., Metallurgical Transactions A, Vo1. 12A, No. 1, Jan. 1981, pp. 57-64.

9. Newman, Jr., J.C., in Behavior of Short Cracks in Airframe Components, AGARD-CP-328, AGARO, Nevilly-Sur-Seine, France, 1982, pp. 6-1 to 6-10.

10. Broek, D., Elementary Engineering Fracture Mechanics, Noordhoff, ist ed., 1974 , p. 320 .

11. Zaiken, E., and Ritchie, 0., Metallurgical Transactions A, Vol. 16A, No. 8, Aug. 1985, pp. 1467-1477.

12. Minakawa K., Newman, J.C., Jr., and McEvily A.E., Fatigue of Engineering Materials and Structures, Vol. 6, No. 4, 1983, pp. 359-365. 
13. Breat, J.L., Mudry, F., and Pineau A., Fatigue of Engineering Materials and Structures, Vol. 6, No. 4, 1983, pp. 349-358.

14. Von Euw, E.F.J., Hertzberg, R.W., and Roberts R., in Stress Analysis and Growth of Circles, ASTM-STP-513, ASTM, Philadelphia, PA, 1972, pp. 230-259.

15. Hudson, C.M., and Hardrath, H.F., "Effects of Changing Stress Amplitude on the Rate of Fatigue-Crack Propagation in Two Aluminum Alloys, "NASA TN D-960, National Aeronautics and Space Administration, Washington, D.C., 1961.

16. Hardrath H.F., and McEvily, A.J., in Crack Propagation Symposium Proceedings, Vol. 1, College of Aeronautics, Cranfield, England, 1962, pp. $231-270$.

17. Schulte, K., Trautmann, H., and Nowack H., in Fatigue Crack Topography, AGARD-CP-376, AGARD, Nevilly-Sur-Seine, France, 1984, pp. 16-1 to 16-10.

18. Fleck, N.A., and Smith, R.A., International Journal of Fatigue, Vol. 4, No. 3 , July 1982, pp. 157-160.

19. Ewalds, H.L., and Furnee, R.T., International Journal of Fracture, Vo1. 14, 1978, pp. R53-R55.

20. Hertzberg, R.W., Deformation and Fracture Mechanics of Engineering Materials, Wiley, New York, 1976, p. 500. 
TABLE 1. - TENSILE PROPERTIES - 7075-T6

\begin{tabular}{|c|c|c|c|c|c|}
\hline \multirow{2}{*}{ Orientation } & \multicolumn{2}{|l|}{ Ultimate strength } & \multicolumn{2}{|c|}{0.2 percent } & Elongation, \\
\cline { 2 - 4 } & MPa & ksi & \multicolumn{2}{c|}{ yield strength } & percent \\
\cline { 4 - 5 } & & & MPa & ksi & \\
\hline Longitudinal & 565 & 82 & 524 & 76 & 12 \\
Long transverse & 579 & 84 & 517 & 75 & 13 \\
\hline
\end{tabular}

TABLE 2 - TEST MATRIX

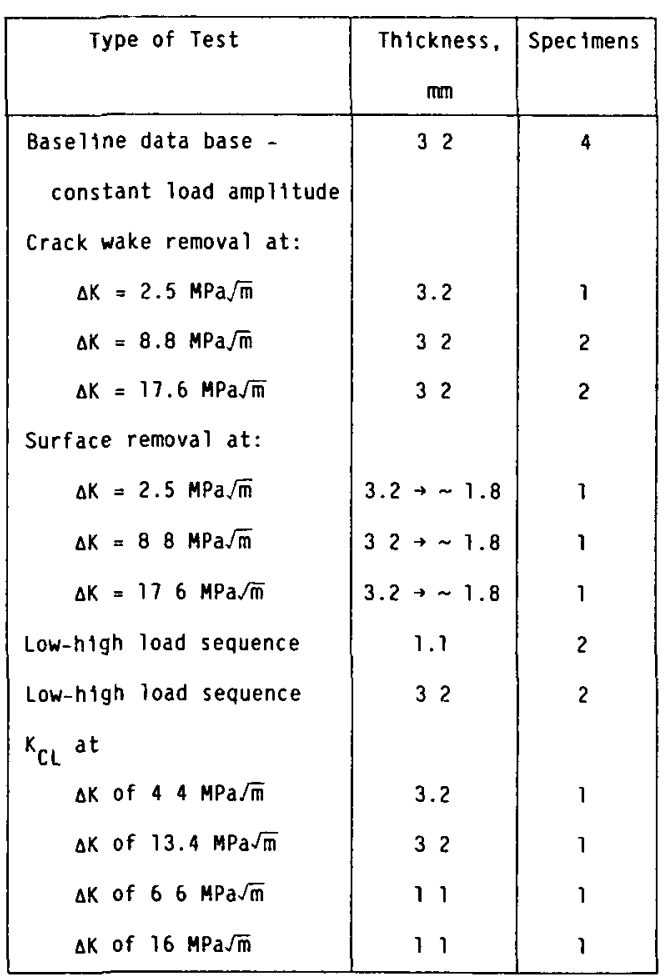


TABLE 3. - PLASTIC ZONE SIZE

\begin{tabular}{|c|c|c|}
\hline $\begin{array}{c}\Delta K \\
M P a \sqrt{m}\end{array}$ & $\begin{array}{c}\text { Plastic } \\
\text { zone size, } \\
\mathrm{mm}\end{array}$ & $\begin{array}{l}\text { Plastic zone } \\
\text { size ratio }\end{array}$ \\
\hline 2.5 & $b_{0.0087}$ & 1 \\
\hline 8.8 & .11 & 12.5 \\
\hline 17.6 & .438 & 50 \\
\hline
\end{tabular}

${ }^{a}$ Calculated by using $r_{p}=1 / \pi\left(k_{m a x} / \sigma_{y s}\right)^{2}$

bunity zone size

TABLE 4 - MEASURE $K_{C L}$ VALUES

\begin{tabular}{|c|c|c|}
\hline $\begin{array}{c}\text { Thickness, } \\
\mathrm{mm}\end{array}$ & $\begin{array}{c}\Delta \mathrm{K} \text { applied, } \\
\mathrm{MPa} \sqrt{\mathrm{m}}\end{array}$ & $\begin{array}{c}\mathrm{K}_{\mathrm{CL}} \\
\mathrm{MPa} \sqrt{\mathrm{m}}\end{array}$ \\
\hline 3.2 & 4.4 & 1.54 \\
3.2 & 13.4 & 2.56 \\
1.1 & 6.6 & 2.3 \\
1.1 & 16.0 & 5.3 \\
\hline
\end{tabular}




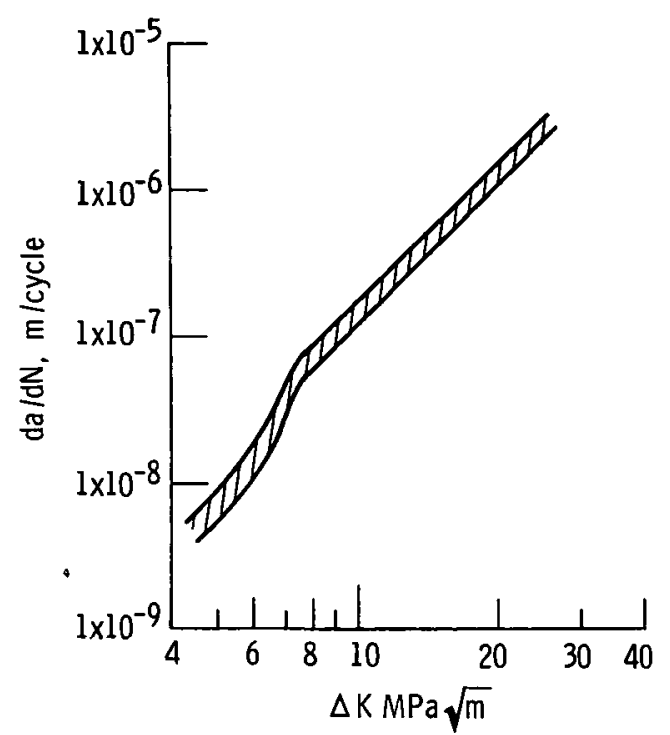

Figure 1. - Baselıne constant amplitude data.

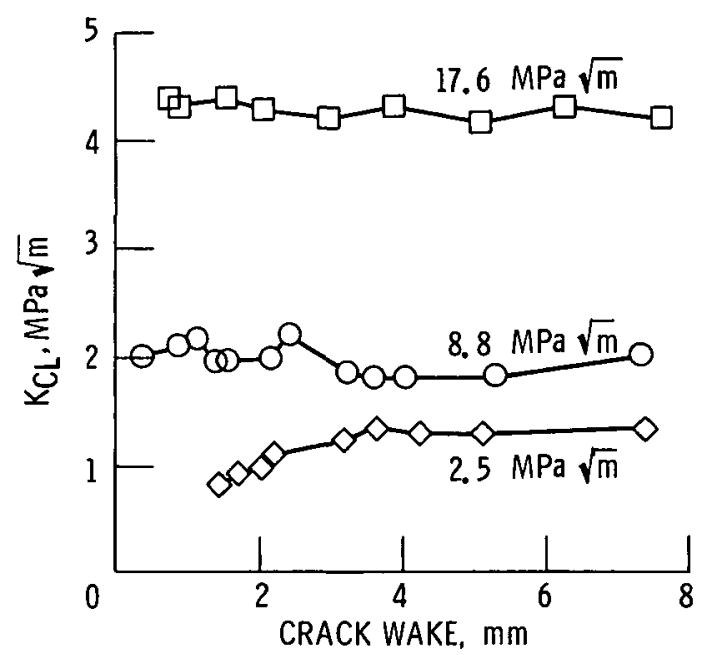

Figure 2. - $\mathrm{K}_{\mathrm{Cl}}$ as a function of crack wake at $\Delta K$ of $2.5,8.8$, and $17.6 \mathrm{MPa} \sqrt{\mathrm{m}}$. 


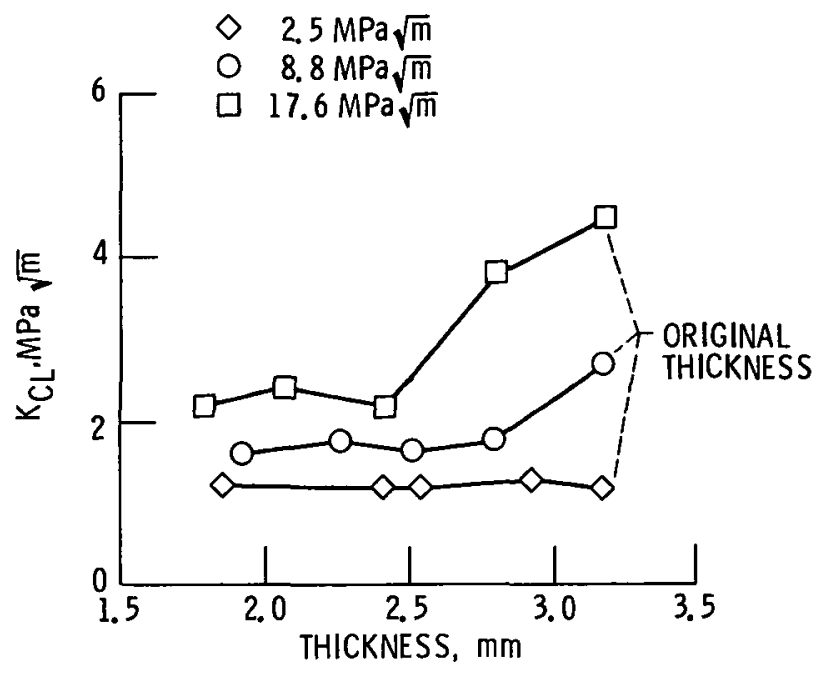

Figure 3. $-\mathrm{K}_{\mathrm{Cl}}$ as a function of specimen thickness after surface removal.

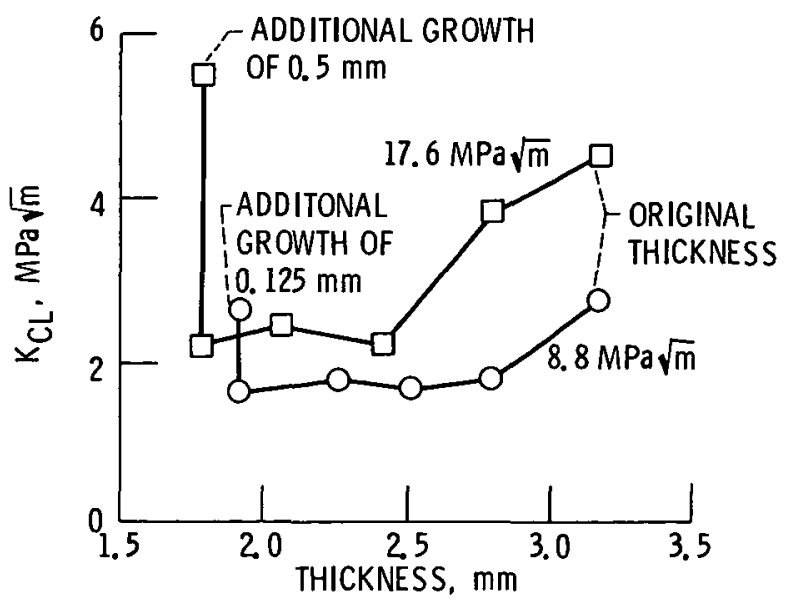

Figure 4. - Increase in $\mathrm{K}_{\mathrm{CL}}$ after reinitiation of crack growth. 


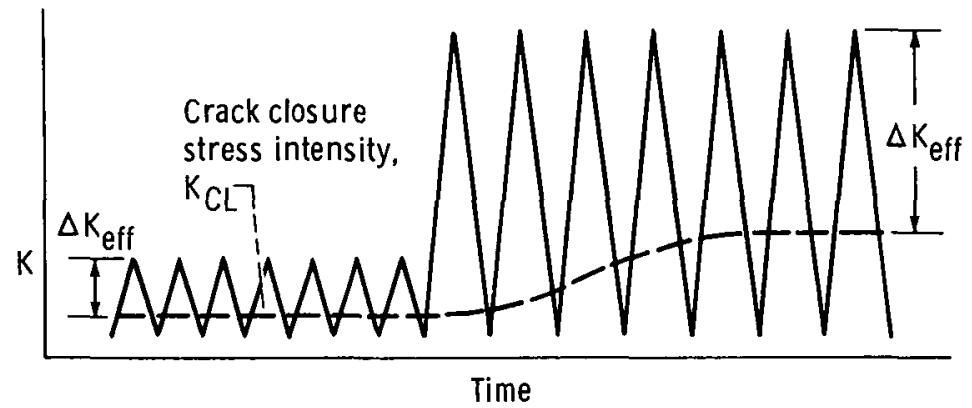

Figure 5. - Schematic showing the proposed increase in $\mathrm{K}_{\mathrm{CL}}$ after transition into higher $\Delta K(20)$.

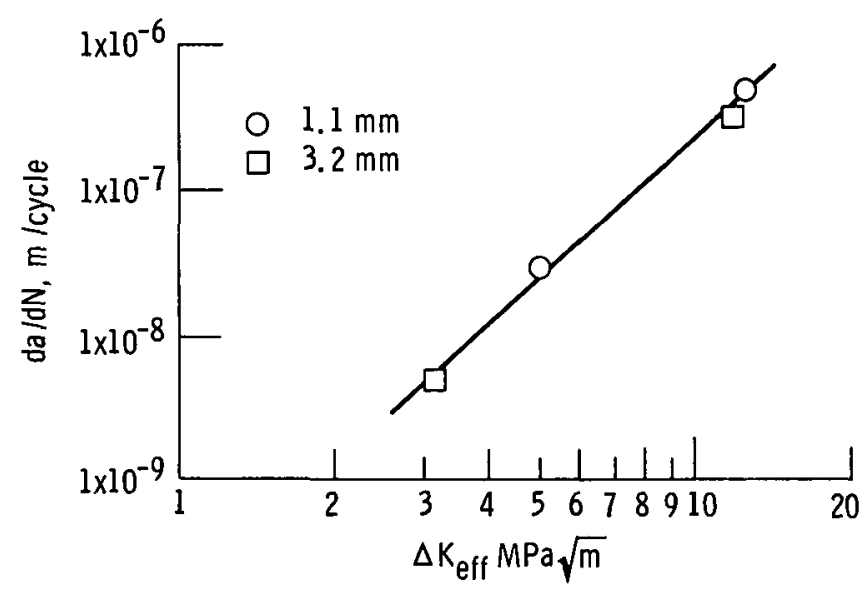

Figure 6. - FCP rates as a function of $\Delta \mathrm{K}_{\text {eff }}$ for both 1.1 and $3.2 \mathrm{~mm}$ thick specimens. 


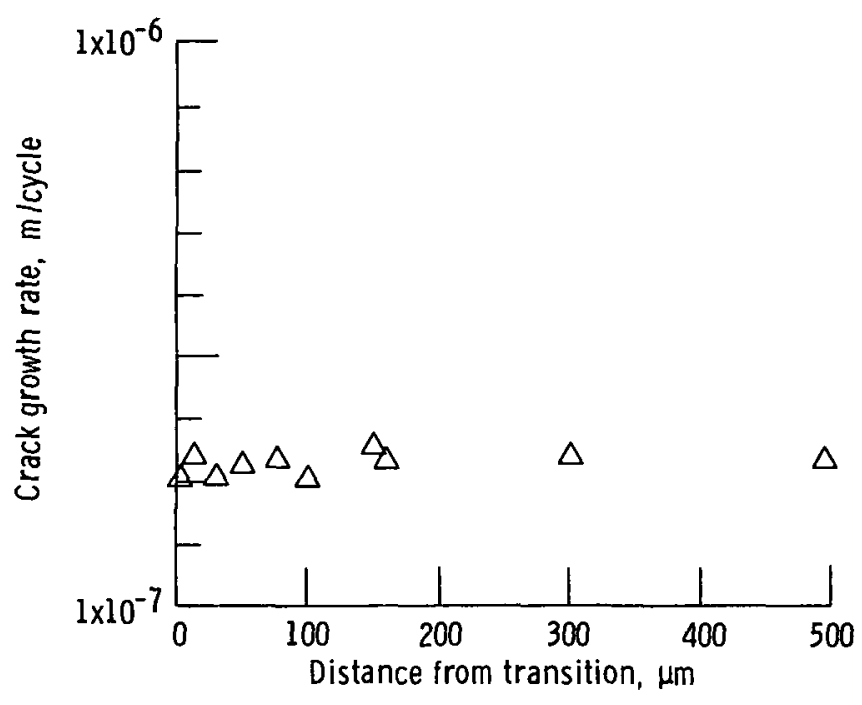

Figure 7. - FCP rates measured from striation spacings in the $3.2 \mathrm{~mm}$ thick specimens.

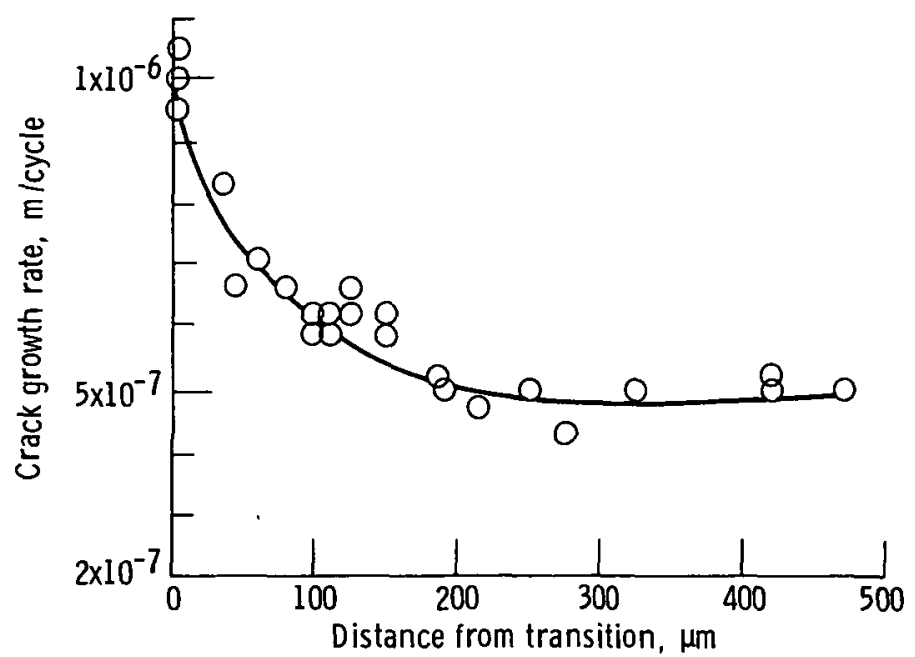

Figure 8. - FCP rates measured from striation spacings in the $1.1 \mathrm{~mm}$ thick specimens. 


\section{ORIGINAL PAGE IS \\ OF POOR OIIALITY}

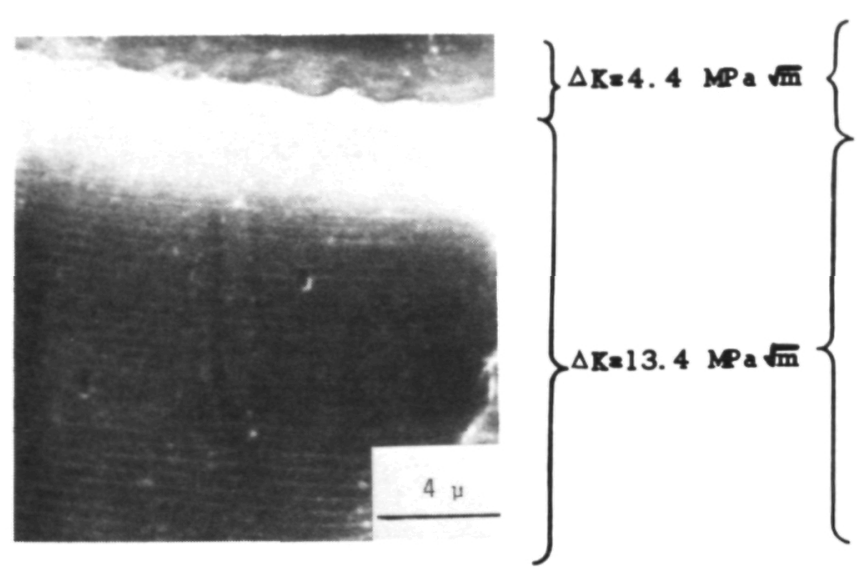

$\mathrm{da} / \mathrm{dn}=3.37 \times 10-7 \mathrm{~m} /$ cycle

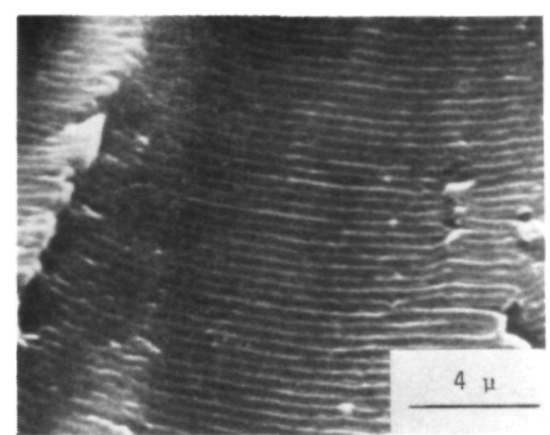

$\mathrm{da} / \mathrm{dn}=3.26 \times 10-7 \mathrm{~m} /$ cycle $50 \mu \mathrm{m}$ FROM TRANSITION

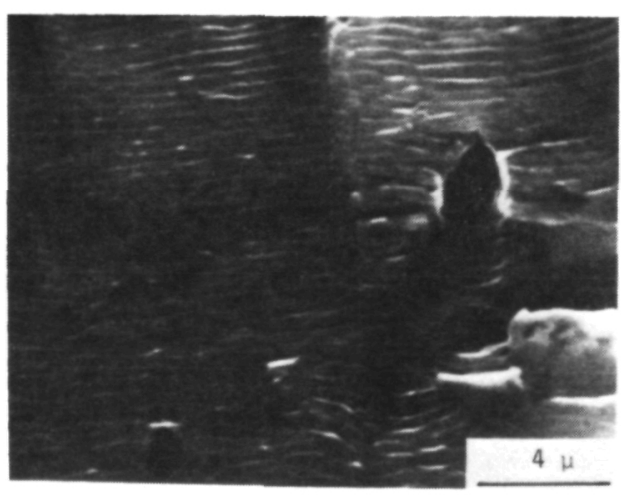

$\mathrm{da} / \mathrm{dn}=3.6 \times 10-7 \mathrm{~m} /$ cycle $150 \mu \mathrm{m}$ FROM TRANSITION

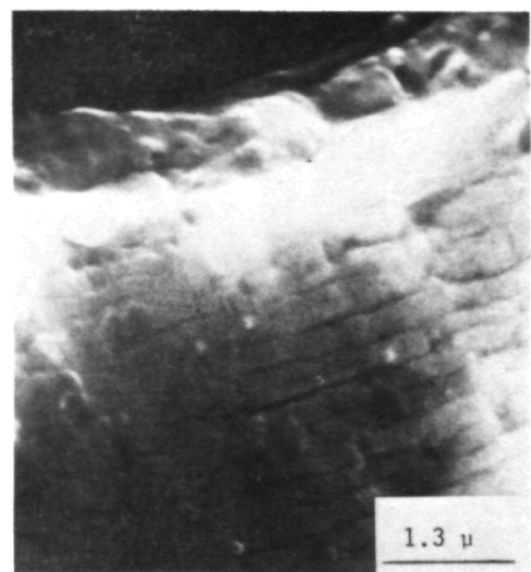

$\mathrm{da} / \mathrm{dn}=3.05 \times 10-7 \mathrm{~m} /$ cycle

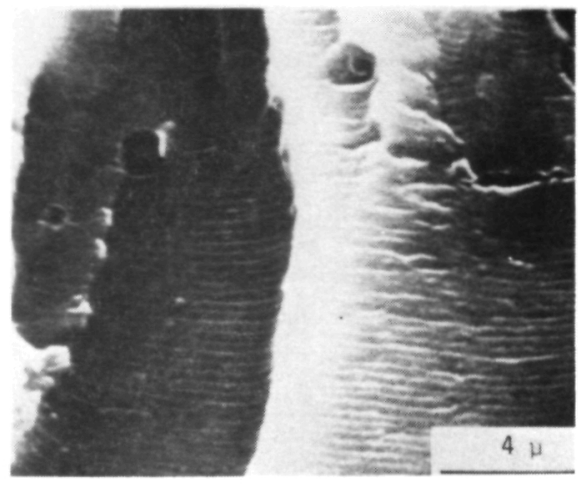

$\mathrm{da} / \mathrm{dn}=3.07 \times 10-7 \mathrm{~m} /$ cycle $100 \mu \mathrm{m}$ FROM TRANSITION

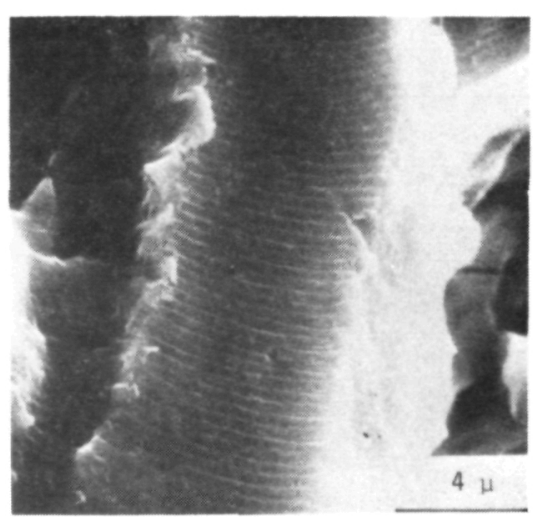

$\mathrm{da} / \mathrm{dn}=3.37 \times 10-7 \mathrm{~m} /$ cycle $2500 \mu \mathrm{m}$ FROM TRANSITION

Figure 9. - Examples of fractographs used to measure FCP rates of $3.7 \mathrm{~mm}$ thick specimens. 


\section{ORIGINAL PAGE IS \\ OF POOR QUALITY}

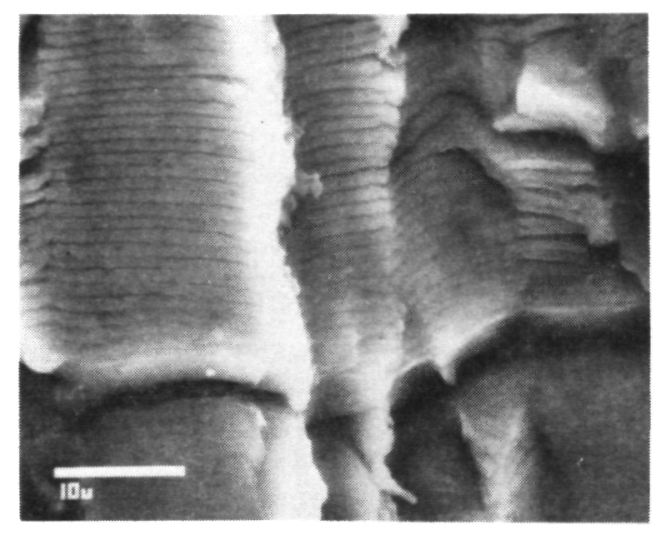

TRANSITION

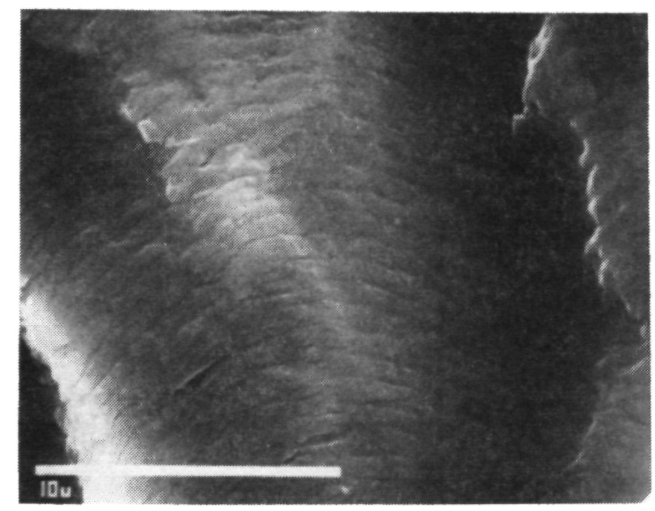

$\mathrm{da} / \mathrm{dn}=7.7 \times 10-7 \mathrm{~m} / \mathrm{cycle}$ $40 \mu \mathrm{m}$ FROM TRANSITION

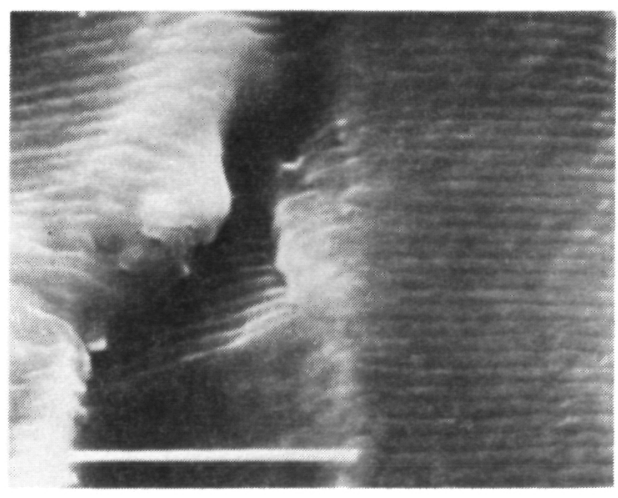

$\mathrm{da} / \mathrm{dn}=5 \times 10-7 \mathrm{~m} /$ cycle $190 \mu \mathrm{m}$ FROM TRANSITION

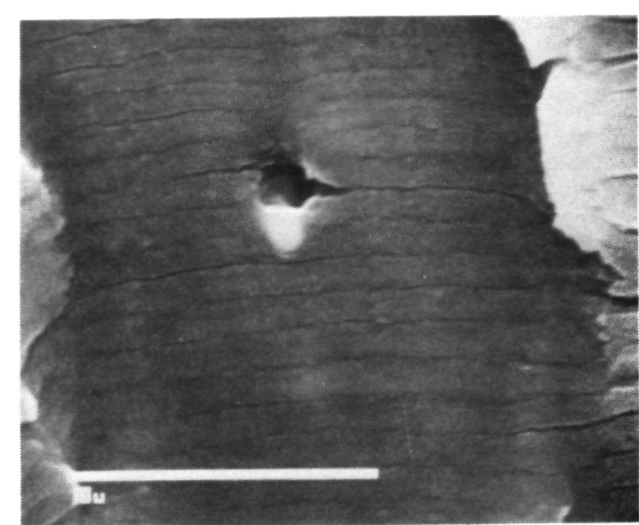

$\mathrm{da} / \mathrm{dn}=1 \times 10-6 \mathrm{~m} /$ cycle AROUND TRANSITION

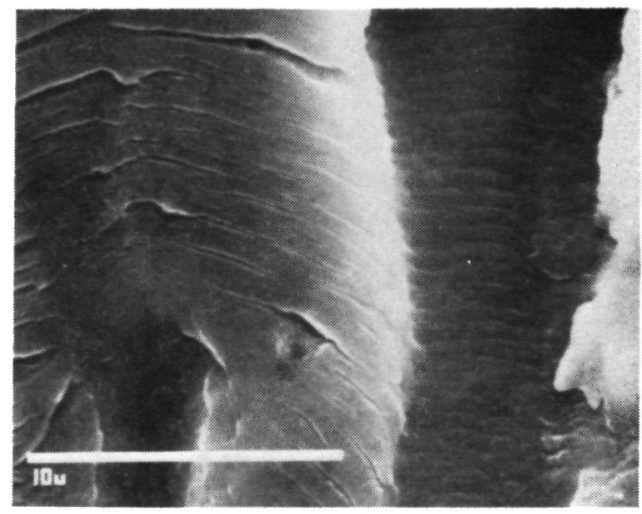

da $/ \mathrm{dn}=6.25 \times 10-7 \mathrm{~m} /$ cycle $110 \mu \mathrm{m}$ FROM TRANSITION

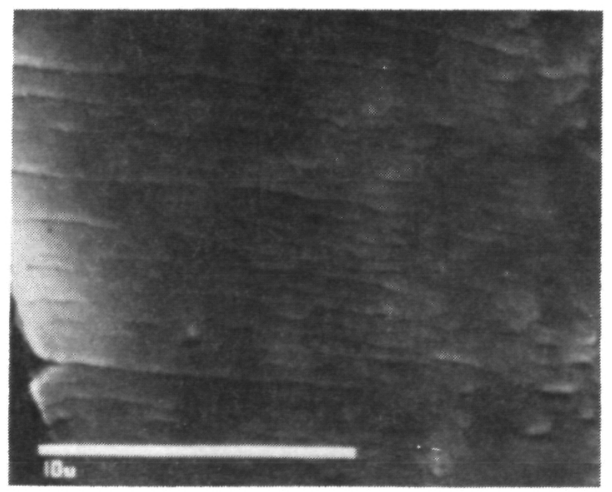

$\mathrm{da} / \mathrm{dn}=5 \times 10-7 \mathrm{~m} /$ cycle $250 \mu \mathrm{m}$ FROM TRANSITION

Figure 10. - Examples of fractographs used to measure FCP rates of $1.1 \mathrm{~mm}$ thick specimen. 


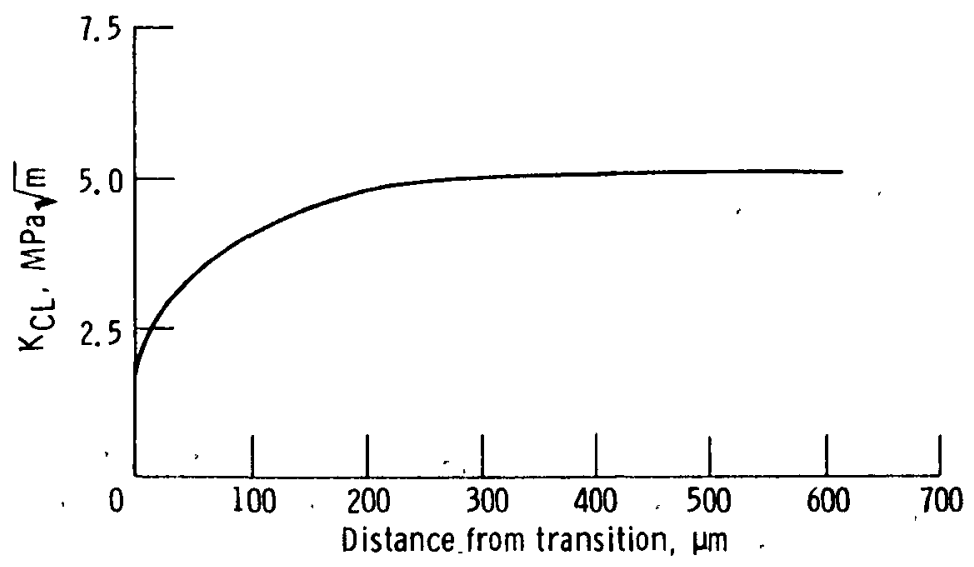

Figure 11.- Calculated $\mathrm{K}_{\mathrm{CL}}$ values as a function of distance from transition into higher $\Delta K$ for $1.1 \mathrm{~mm}$ thıck specimens. 


\begin{tabular}{|c|c|c|}
\hline $\begin{array}{l}1 \text { Report No } \\
\text { NASA TM- } 87292 \\
\end{array}$ & 2 Government Accession No & 3 Recipient's Catalog No. \\
\hline \multicolumn{2}{|c|}{$\begin{array}{l}4 \text { Title and Subtitle } \\
\text { Influence of Fatigue Crack Wake Length and State of } \\
\text { Stress on Crack Closure }\end{array}$} & $\begin{array}{l}\text { 6. Performing Organization Code } \\
505-33-7 C\end{array}$ \\
\hline \multirow{2}{*}{\multicolumn{2}{|c|}{7 Author(s) }} & $\begin{array}{l}8 \text { Performing Organization Report No } \\
\text { E-2999 }\end{array}$ \\
\hline & & 10 Work Unit No \\
\hline \multicolumn{2}{|c|}{$\begin{array}{l}9 \text { Performing Organization Name and Address } \\
\text { National Aeronautics and Space Administration } \\
\text { Lewts Research Center } \\
\text { Cleveland, Ohio } 44135\end{array}$} & 11 Contract or Grant No \\
\hline \multicolumn{2}{|l|}{12 Sponsoring Agency Name and Address } & 14 Sponsoring Agency Code \\
\hline \multicolumn{3}{|c|}{$\begin{array}{l}15 \text { Supplementary Notes } \\
\text { Prepared for the International Symposium on Fatigue Crack Closure, sponsored by } \\
\text { the American Society for Testing and Materials, Charleston. South Carolina, } \\
\text { May } 1-2,1986 .\end{array}$} \\
\hline \multicolumn{3}{|c|}{$\begin{array}{l}16 \text { Abstract } \\
\text { The location of crack closure with respect to crack wake and specimen thickness } \\
\text { under different loading conditions was determined. The rate of increase of } \mathrm{K}_{\mathrm{CL}} \\
\text { in the crack wake was found to be slgniflcantly higher for plasticity induced } \\
\text { closure in comparison to roughness induced closure. Roughness induced closure } \\
\text { was uniform throughout the thickness of the specimen while plasticity induced } \\
\text { closure levels were } 50 \text { percent higher in the near surface region than in the } \\
\text { mid-thickness. The influence of state of stress on low-high load interaction } \\
\text { effects was also examined. Load interaction effects differed depending upon the } \\
\text { state of stress and were explained in terms of akeff. }\end{array}$} \\
\hline $\begin{array}{l}17 \text { Key Words (Suggested by Author(s)) } \\
\text { Crack c losure } \\
\text { Fat igue crack growth } \\
\text { Load interactions }\end{array}$ & \begin{tabular}{r|r}
18 Distribution S \\
Unclassi \\
STAR Cat
\end{tabular} & $-\operatorname{un}_{26} i 1 \mathrm{mited}$ \\
\hline $\begin{array}{l}19 \text { Security Classif (of this report) } \\
\text { Unc lass if ied }\end{array}$ & $\begin{array}{l}\text { Security Classif (of this page) } \\
\text { Unc las sif ied }\end{array}$ & \begin{tabular}{|l|l|}
21 No. of pages & 22 Price $^{*}$
\end{tabular} \\
\hline
\end{tabular}

"For sale by the Natıonal Technical Information Service. Sprıngfield, Virginıa 22161 
National Aeronautics and

Space Administration

Lewis Research Center

Cleveland Ohio 44135

Official Business

Penaly for Private Use $\mathbf{5 0 0}$
SECOND CLASS MAIL

ADORESS CORRECTION REQUESTED

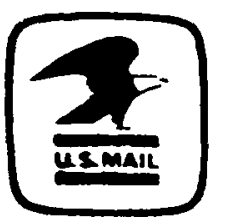

Postage and Fees Paid National Aeronautics and

Space Administration NASA-451 